OPEN ACCESS

Edited by:

Xufeng Jing,

China Jiliang University, China

Reviewed by:

Xiaojian $\mathrm{Fu}$

Southeast University, China

Shobhit K. Patel,

Marwadi University, India

Fenglong Wang,

Shandong University, China

*Correspondence:

Guoyan Dong

gydong@ucas.ac.cn

$\mathrm{Ke} \mathrm{Bi}$

bike@bupt.edu.cn

†These authors have contributed equally to this work

Specialty section:

This article was submitted to

Optics and Photonics,

a section of the journal

Frontiers in Physics

Received: 14 May 2020

Accepted: 22 June 2020

Published: 04 September 2020

Citation:

Yao H, Liu X, Zhu H, Li H, Dong G and

Bi K (2020) Dual-Band Microstrip

Antenna Based on Polarization

Conversion Metasurface Structure.

Front. Phys. 8:279

doi: 10.3389/fphy.2020.00279

\section{Dual-Band Microstrip Antenna Based on Polarization Conversion Metasurface Structure}

\author{
Huiming Yao ${ }^{1 \dagger}$, Xinyi Liu ${ }^{1 \dagger}$, Hongbo Zhu ${ }^{1}$, Haihong $\mathrm{Li}^{1}$, Guoyan Dong ${ }^{2 \star}$ and $\mathrm{Ke} \mathrm{Bi}{ }^{1,3 *}$ \\ ${ }^{1}$ School of Science, Beijing University of Posts and Telecommunications, Beijing, China, ${ }^{2}$ College of Opto-Electronic \\ Technology, University of Chinese Academy of Sciences, Beijing, China, ${ }^{3}$ Beijing University of Posts and Telecommunications \\ Research Institute, Shenzhen, China
}

A dual-band microstrip patch antenna (MPA) based on a polarization conversion metasurface structure was designed. By etching the complementary split ring resonator (CSRR) on the ground plane, a new resonance frequency is generated. The proposed antenna is obtained through optimizing the structural parameters of CSRR. Compared with the antenna without CSRR, the return loss of the proposed antenna increases by $\sim 40 \%$ at the original resonance frequency. The measured results are similar to the simulated results, verifying the reliability of the antenna. This work introduces a new way of designing multi-band antenna.

\section{Keywords: microstrip antenna, dual-band, polarization conversion, metasurface structure, complementary split ring resonator}

\section{INTRODUCTION}

An antenna plays an important role in modern wireless communication systems. In recent years, the miniaturization and multi-functionalization of communication devices require that the internal antenna has strong integration capabilities [1,2]. Meanwhile, owing to the lack of wireless spectrum resources, the demand for multi-band antenna has increased [3-5]. Microstrip patch antenna (MPA) are extensively used due to their advantages of small size, simple structure, low cost, and ease of integration $[6,7]$. Many methods have been studied to obtain multi-band antenna, such as coupling feed technologies [8], slot-loaded technologies [9], and reconfigurable technologies $[10,11]$. Unfortunately, these methods require complex calculation, and the antenna structures are difficult to manufacture. Thus, new designs should be explored to simplify the structure and theoretical analysis.

Metasurface, due to its extraordinary electromagnetic properties, is widely used in antenna design [12-14], namely in the realization of multi-band [15, 16], ultra-wide-band [17-19], and high-gain antenna [20,21]. In most cases, the metasurface structure is loaded on the antenna as a radiating element. The capability of a multi-band operation is not currently apparent. Many efforts have been made to solve this problem, such as etching a complementary split ring resonator (CSRR) on the ground plane. The CSRR unit cell can resonate with an electromagnetic wave, resulting in new resonance peaks. Ali et al. [22] created a triple-band antenna by etching rectangular and circular CSRRs. Zhou et al. [23] fabricated a composite right/left-handed structure as the radiating element and employed a square CSRR to get a dual-band antenna. Xu et al. [24] used a simple square split ring resonator to design an ultra-broad-band linear polarization converter, which provided a way to change the antenna polarization mode. We have recently obtained a broadband microstrip patch antenna by using a complementary rhombus resonator [25]. 
In this work, we designed a dual-band MPA loaded with a CSRR structure. The CSRR serves as a resonator. From the simulated results, it is found that the MPA exhibits excellent performance within the dual-band resonance in the range of 3.07.5 GHz. The measured results are similar to the simulated ones, which proves that the proposed antenna can be well-applied to physical devices.

\section{ANTENNA DESIGN}

C-band antenna have been widely used in satellite communication and navigation [26]. Therefore, we designed an antenna operating at $6.9 \mathrm{GHz}$. The top and back view of the antenna are, respectively, shown in Figures 1A,B. The upper layer of the antenna consists of a rectangular patch, and two different-width feedlines. The middle layer is an FR4 substrate with a relative dielectric constant of 2.65 and the lower layer is a metal ground plane. In order to realize the design of the dual-band antenna, the ground plane is modified. As shown in Figure 1C, CSRR was etched on the ground plane which is used to generating new resonance frequency. To further improve the electromagnetic performance of the antenna, a series of parameter optimization was carried out, and the ground plane of the proposed antenna is shown in Figure 1D.
The simulated results of the proposed antenna are shown in Figure 2, with a series of side length $r$, split width $d$, rotation angle $\theta$, and distance $h$. It can be seen that the original resonance frequency is affected by length $r$, split width $d$, and rotation angle $\theta$, while the new resonance frequency is mainly tuned by distance $h$. According to Figure 2A, as $r$ increases from 15.0 to $16.5 \mathrm{~mm}$, the original resonance frequency moves to the lower frequency. When $r=16.0 \mathrm{~mm}$, the return loss at the original resonance frequency is maximum. Figure 2B demonstrates that, as $d$ increases from 0 to $4.5 \mathrm{~mm}$, the original resonance frequency moves to the higher frequency. When $d=0$, which means CSRR is a closed ring, the original resonance disappears. At this time, the antenna only works in S-band. As displayed in Figure $2 \mathrm{C}$, when $\theta$ increases from 0 to $45^{\circ}$, the original resonance frequency moves to the lower frequency. Moreover, when $\theta=$ $30^{\circ}$, the return loss at the original resonance frequency reaches maximum. Figure 2D depicts that, as $h$ increases from 24.0 to $25.5 \mathrm{~mm}$, the new resonance frequency moves to the lower frequency. When $h=24.5 \mathrm{~mm}$, the return loss at new resonance point is at its maximum, now the centers of CSRR and the substrate coincide. Considering the performance of antenna comprehensively, we designed the ground plane of the proposed antenna as Figure 1D. The parameters of the proposed antenna are listed in Table $\mathbf{1 .}$

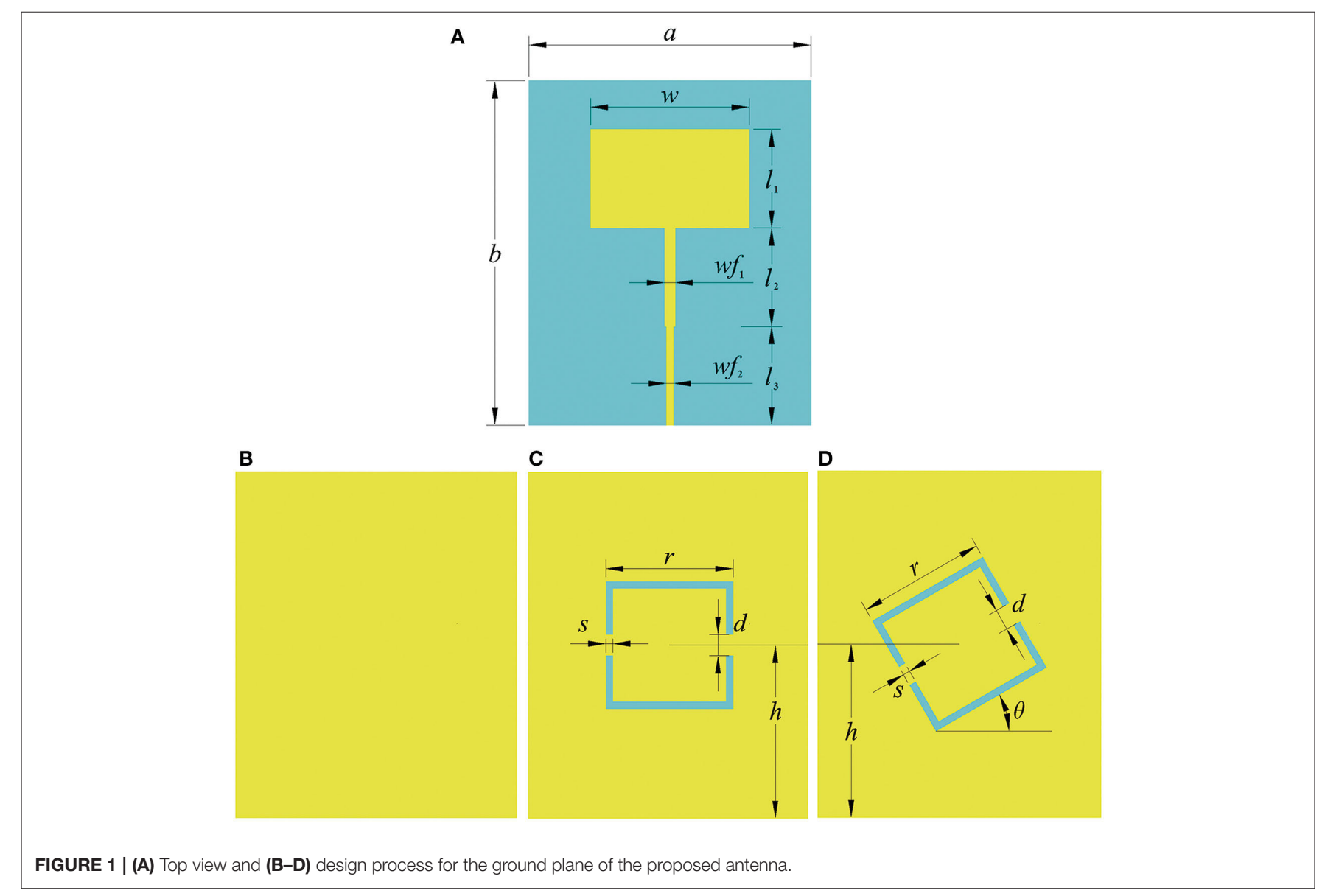




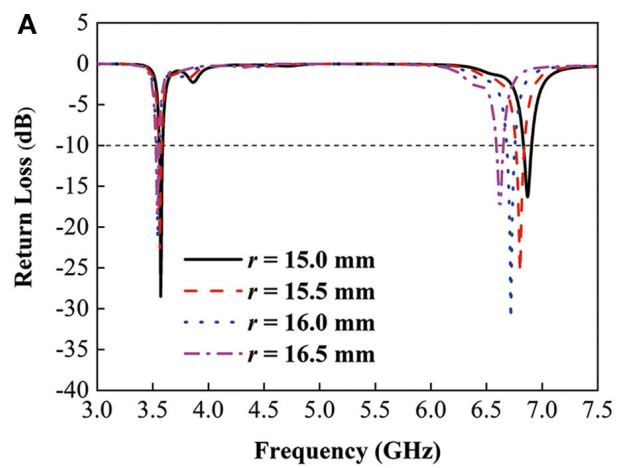

C

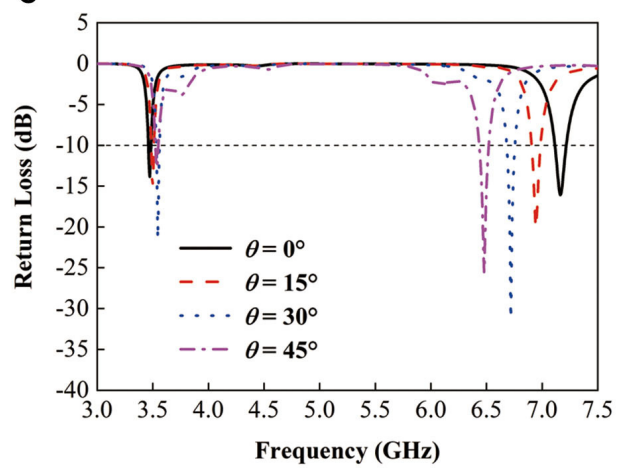

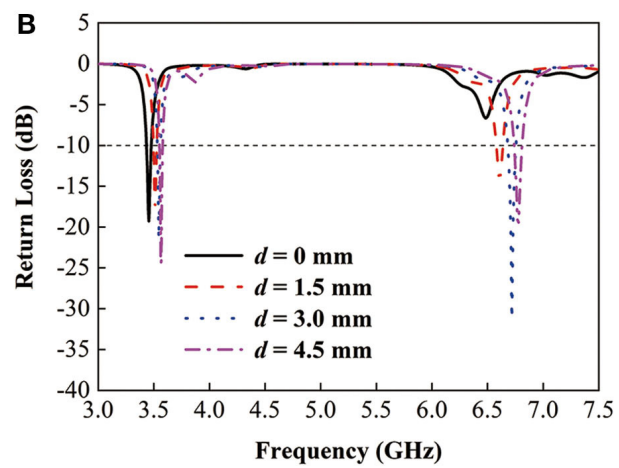

D

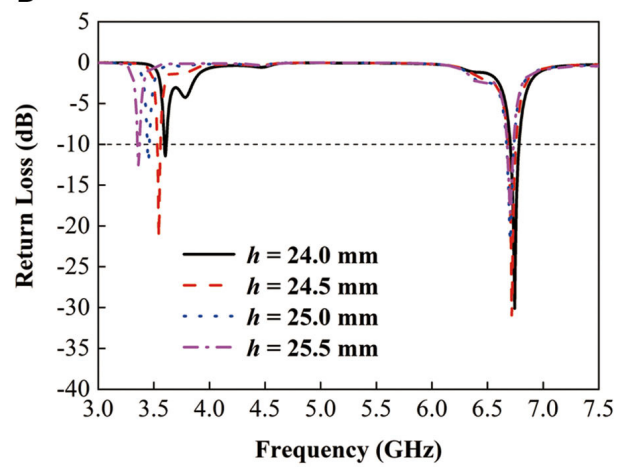

FIGURE 2 | Return loss of the proposed antenna with a series of (A) side length $r$; (B) split width $d$; (C) rotation angle $\theta$; (D) distance $h$.

TABLE 1 | Parameters of the proposed antenna.

\begin{tabular}{lccc}
\hline Parameter & Value & Parameter & Value \\
\hline$a$ & $40.0 \mathrm{~mm}$ & $b$ & $49.0 \mathrm{~mm}$ \\
$t$ & $1.5 \mathrm{~mm}$ & $w$ & $22.5 \mathrm{~mm}$ \\
$w f_{1}$ & $1.5 \mathrm{~mm}$ & $w f_{2}$ & $1.0 \mathrm{~mm}$ \\
$t_{1}$ & $0.035 \mathrm{~mm}$ & $I_{1}$ & $14.0 \mathrm{~mm}$ \\
$I_{2}$ & $14.0 \mathrm{~mm}$ & $I_{3}$ & $14.0 \mathrm{~mm}$ \\
$r$ & $16.0 \mathrm{~mm}$ & $d$ & $3.0 \mathrm{~mm}$ \\
$s$ & $1.0 \mathrm{~mm}$ & $h$ & $24.5 \mathrm{~mm}$ \\
$\theta$ & $30^{\circ}$ & & \\
\hline
\end{tabular}

To intuitively illustrate the effect of CSRR on the antenna frequency band, the return loss of the original antenna and the proposed antenna are compared. As shown in Figure 3, it can be inferred that the proposed antenna has a new resonance peak centered at $3.54 \mathrm{GHz}$ with a return loss of $21.4 \mathrm{~dB}$. The original resonance frequency shifts from 6.87 to $6.72 \mathrm{GHz}$, and its return loss increases from 22.1 to $31.2 \mathrm{~dB}$.

\section{RESULTS AND DISCUSSION}

In order to explain the work principle of CSRR, the surface current distribution of the antenna is observed. Figure 4 shows the surface current distribution of the antenna without CSRR at 6.87 and $5.00 \mathrm{GHz}$. From Figures 4A,B, we can see that the current density at $6.87 \mathrm{GHz}$ is higher than $5.00 \mathrm{GHz}$. It can be

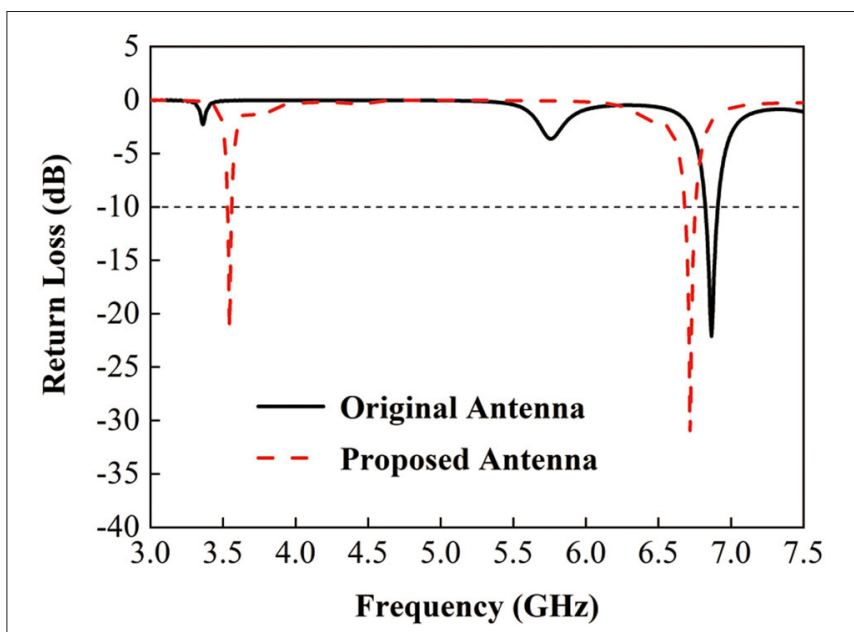

FIGURE 3 | Return loss of the original antenna and the proposed antenna.

deduced that the electromagnetic wave of a specific frequency is excited by the rectangular patch and the feedlines, resulting in resonance at $6.87 \mathrm{GHz}$.

Figure 5 shows the surface current distribution of the antenna with CSRR at two resonance frequencies. It can be observed that the current is no longer limited between the radiation patch and feedlines. It also distributes around CSRR, which demonstrates that the CSRR can act as a resonator to generate new resonance peak. Obviously, etching CSRR damages the structure of the 
ground plane, so that the current distribution is changed. Moreover, the current shocks back and forth in the CSRR, radiating a specific frequency of electromagnetic wave. However, there are some differences in the surface current distribution of Figures 5A,B. At the frequency of $3.54 \mathrm{GHz}$, the surface current

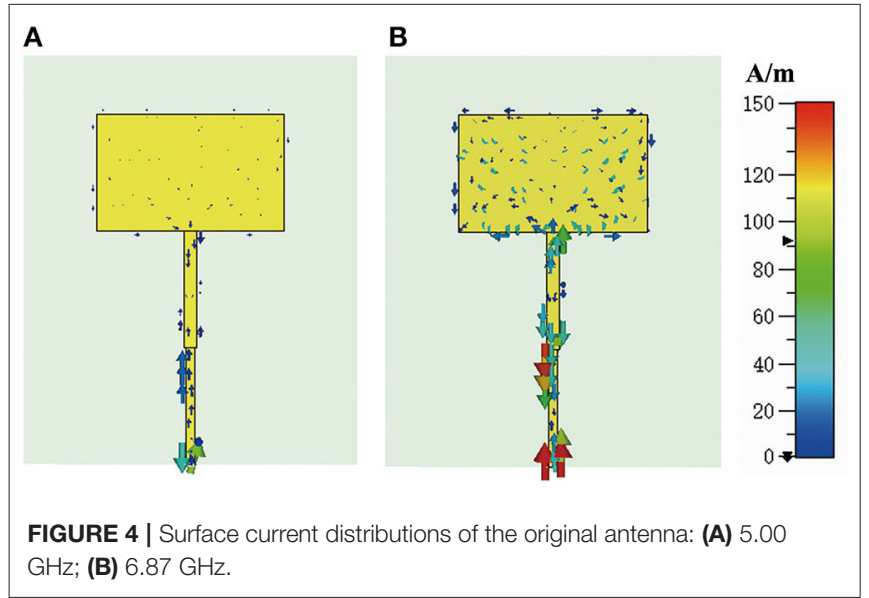

mainly distributes around the CSRR. Thus, the new generated resonance peak is mainly affected by the parameters of the CSRR. Similarly, the resonance peak centered at $6.72 \mathrm{GHz}$ is modulated by the rectangle patch and CSRR.

In order to figure out why CSRR can be used as a resonator, a few more details are exhibited. Comparing the results shown in Figure 5, it can be observed that the surface current distributes around the whole CSRR at $3.54 \mathrm{GHz}$, while only the lower half of CSRR has a current distribution at $6.72 \mathrm{GHz}$. It can be inferred that CSRR serves as a frequency-controlled switch which only opens at specific frequencies. When the switch is closed, the current in the CSRR shocks back and forth, resulting in new resonance within the antenna at $3.54 \mathrm{GHz}$. When the switch is on, the electromagnetic wave is only generated by the lower section of CSRR and it couples with the antenna radiating element, resulting in the original resonance point shifting by $\sim 0.15 \mathrm{GHz}$. Combining with the return loss diagram in Figure 3, it can be concluded that the return loss at the resonance frequency increases by $\sim 40 \%$.

CSRR can not only produce resonance peaks as a resonator, but also affect the radiation characteristics of the antenna. To analyze the effect of CSRR on the polarization mode, the
A

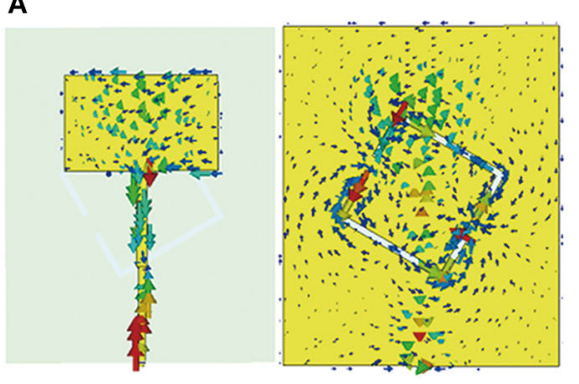

B

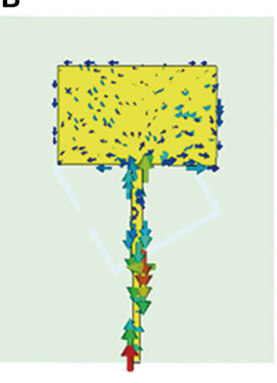

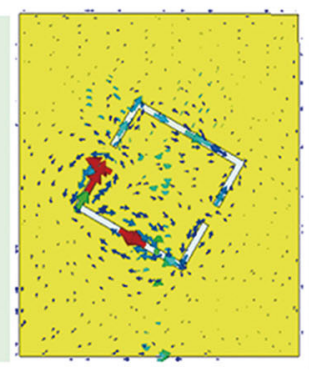

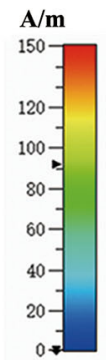

FIGURE 5 | Surface current distributions of the proposed antenna: (A) $3.54 \mathrm{GHz}$; (B) $6.72 \mathrm{GHz}$.

\section{A}

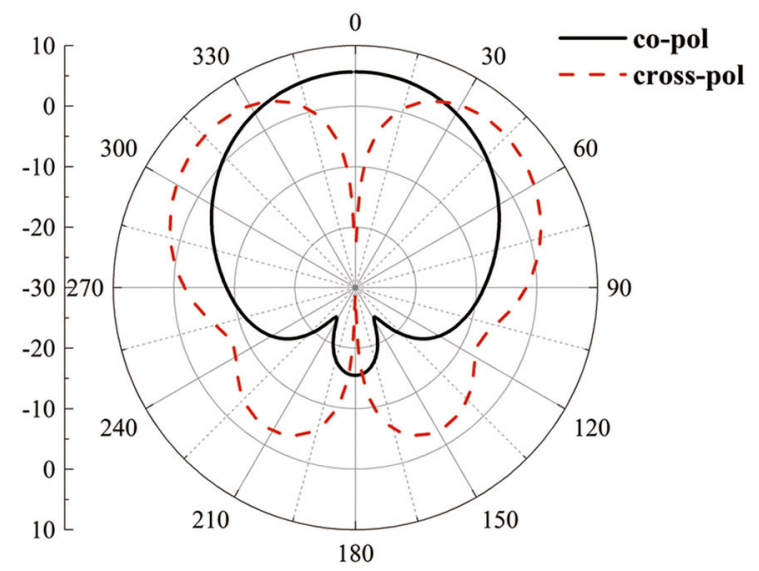

B

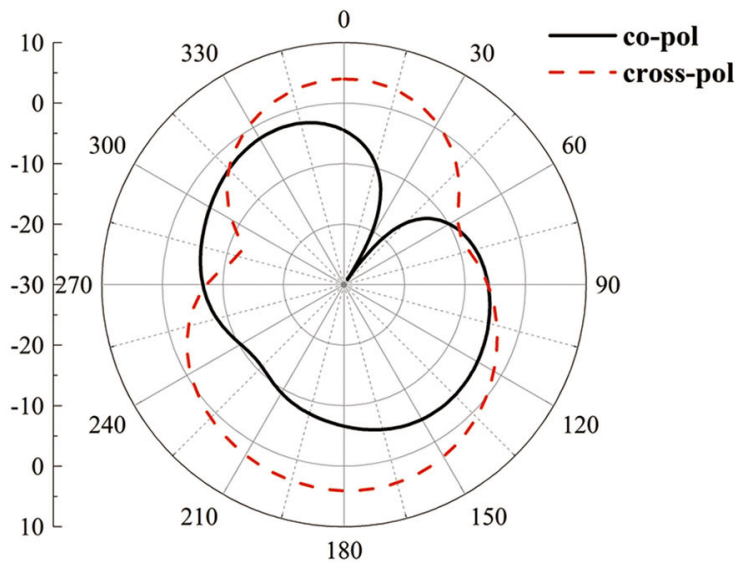

FIGURE 6 | Polarization direction of the antenna: (A) $6.87 \mathrm{GHz}$ (the original antenna); (B) $6.72 \mathrm{GHz}$ (the proposed antenna). 

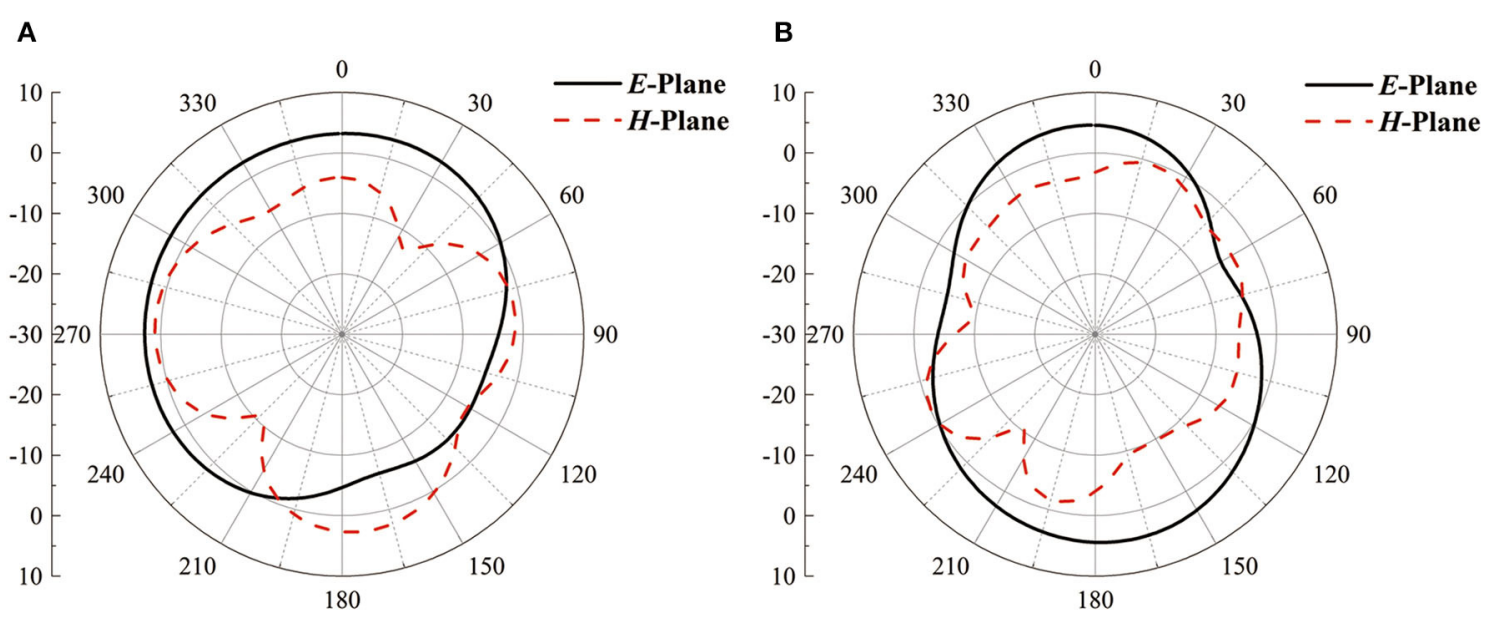

FIGURE 7 | Radiation patterns of the proposed antenna: (A) $3.54 \mathrm{GHz}$; (B) $6.72 \mathrm{GHz}$.
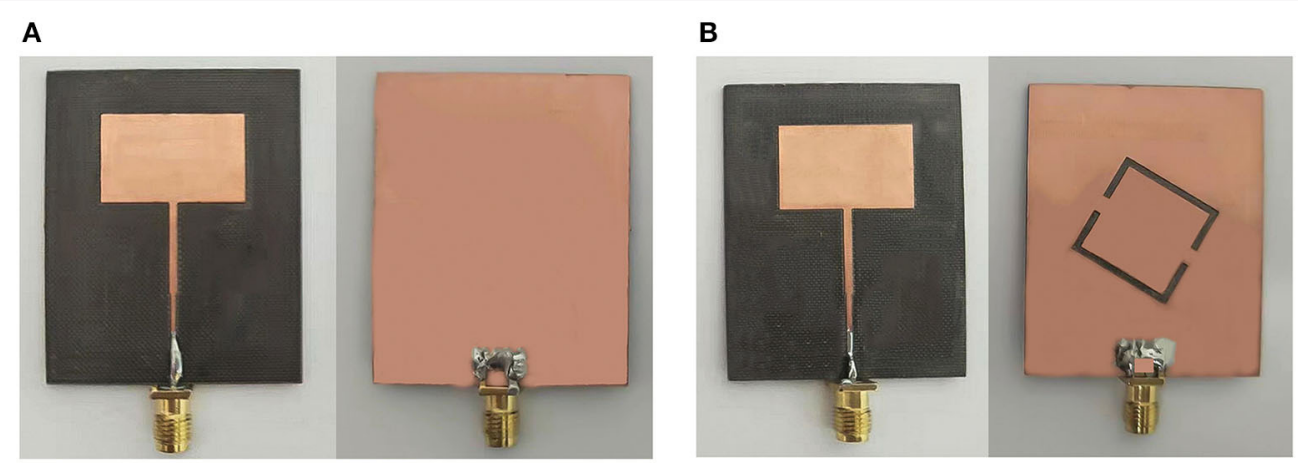

FIGURE 8 | Photographs of the fabricated antenna: (A) the original antenna; (B) the proposed antenna.
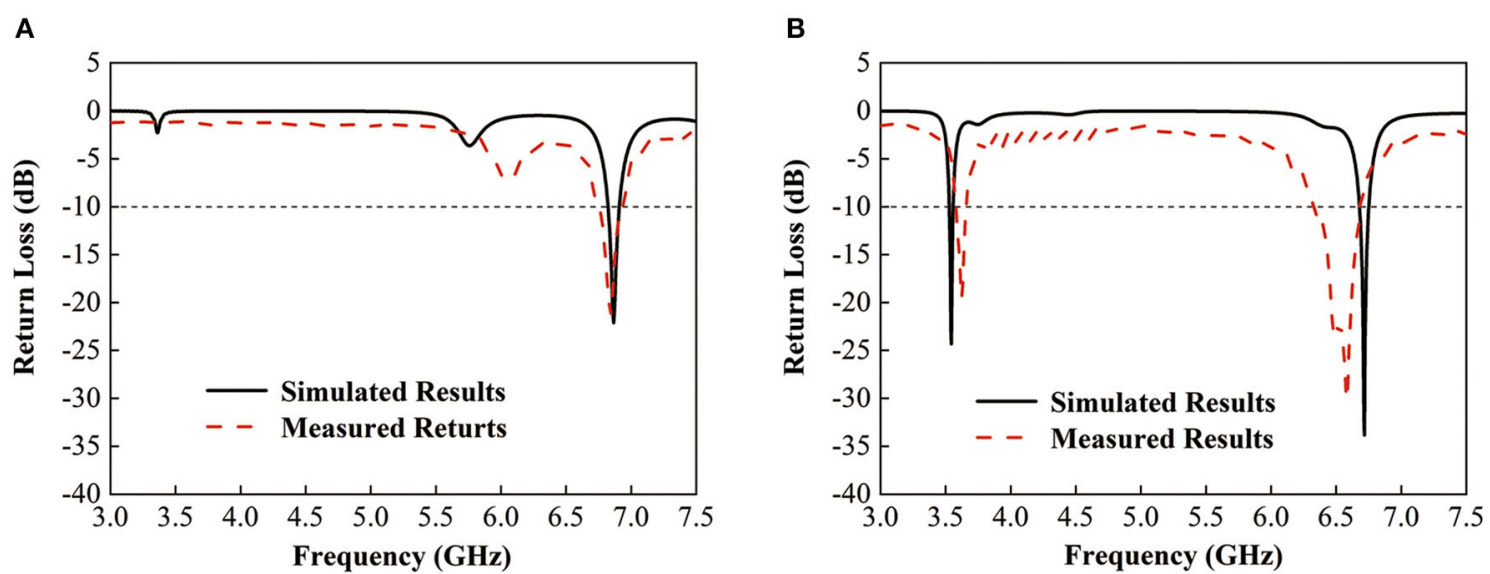

FIGURE 9 | Simulated and measured return loss of the antenna: (A) the original antenna; (B) the proposed antenna.

polarization direction of the antenna with and without CSRR are shown in Figure 6. Figure 6A shows that the polarization direction of the antenna without CSRR is symmetrical at 6.87
$\mathrm{GHz}$, while Figure $6 \mathrm{~B}$ indicates that the symmetry of the antenna with CSRR is broken at $6.72 \mathrm{GHz}$. It can be interpreted that the polarization mode of antenna is highly related to its 
TABLE 2 | Comparison of the antenna performances of this work and the previous literatures.

\begin{tabular}{|c|c|c|c|c|}
\hline References & $\begin{array}{l}\text { Antenna size } \\
\qquad\left(\mathrm{mm}^{2}\right)\end{array}$ & $\begin{array}{l}\text { Number of } \\
\text { resonance } \\
\text { peaks }\end{array}$ & $\begin{array}{l}\text { Operating } \\
\text { frequency } \\
\text { band }\end{array}$ & $\begin{array}{c}\text { Resonance } \\
\text { frequencies }(\mathrm{GHz}) / \\
\text { Peak gain }(\mathrm{dBi})\end{array}$ \\
\hline [8] & $50 \times 58$ & 4 & S, C, X & $\begin{array}{l}2.1 / 1.30 \\
3.3 / 1.59 \\
5.3 / 2.12 \\
7.5 / 3.73\end{array}$ \\
\hline [14] & $5 \times 5$ & 1 & C & - \\
\hline [22] & $60 \times 60$ & 3 & S, C & $\begin{array}{l}2.45 / 1.03 \\
3.56 / 5.10 \\
5.60 / 5.41\end{array}$ \\
\hline This work & $40 \times 49$ & 2 & S, C & $\begin{array}{c}3.54 / 4.78 \\
6.72 / 4.65\end{array}$ \\
\hline
\end{tabular}

structure and changes within the structure. In order to better evaluate the antenna performance, the radiation patterns of the proposed antenna at resonance points are investigated as shown in Figure 7. It can be seen that the radiation patterns in $H$ Plane are almost omnidirectional and the radiation patterns in E-Plane are monopole-like. In addition, the distortion of the radiation patterns is extremely slight, which proves that the introduction of CSRR has almost no effect on the performance of the antenna.

To verify the simulated results, the original antenna and the proposed antenna are fabricated, measured, and compared. A circuit board engraving machine is used to fabricate the antenna and a vector network analyzer (VNA) is used to measure the electromagnetic properties of the antenna. The fabricated antenna are shown in Figure 8. The simulated and measured return loss of the original antenna and the proposed antenna are shown in Figure 9. From Figure 9A, the two curves have a nearly consistent trend and the resonance peaks almost coincide. As depicted in Figure 9B, the two measured resonance frequencies move from 3.54 and $6.72 \mathrm{GHz}$ to 3.62 and $6.58 \mathrm{GHz}$, respectively. Compared with the simulated curves, the return loss decreases by $3-4 \mathrm{~dB}$. Considering the inevitable errors in the process of antenna manufacturing, welding, and measuring, the above deviation can be ignored. Similarly, the fact that the bandwidth of measured curves is broader than the simulated curves is also due to fabrication and measurement errors. Therefore, the measured results correlate with the simulated ones, which proves the reliability of the antenna.

\section{REFERENCES}

1. El-Halaoui M, Kaabal A, Asselman H, Ahyoud S, Asselman A. Multiband planar inverted-F antenna with independent operating bands control for mobile handset applications. Int $J$ Antennas Propag. (2017) 2017:8794039. doi: 10.1155/2017/87 94039

2. Huang S, Guo B, Liu Y. 5G-oriented optical underlay network slicing technology and challenges. IEEE Commun Mag. (2020) 58:13. doi: 10.1109/MCOM.001.1900583
Based on the above analysis, it can be summarized that an antenna etched with CSRR performs excellently despite being small in size and containing a simple structure. Furthermore, we compared the dual-band antenna designed in this work with other literature $[8,14,22]$ in terms of size, number of resonance peaks, operating frequency bands, and peak gain, as listed in Table 2. It is observed that, in other works, multi-band antenna are larger, while small size antenna operate at single-band. The design of our work realizes both miniaturization and multi-band in an antenna, which widens the possibilities for multi-band antenna design.

\section{CONCLUSION}

In conclusion, a dual-band MPA etched with CSRR was designed. The proposed antenna with high performance was obtained by optimizing the structural parameters of CSRR. Based on the simulated results of surface current distribution, it was found that the current shocks back and forth in the CSRR, generating a new resonance peak. By adjusting the rotation angle of the CSRR, an obvious resonance frequency appears. Moreover, the consistency between the simulation and the recorded measurement demonstrates the validity of the design. This work provides a new way to design multi-band antenna.

\section{DATA AVAILABILITY STATEMENT}

The raw data supporting the conclusions of this article will be made available by the authors, without undue reservation.

\section{AUTHOR CONTRIBUTIONS}

$\mathrm{HY}, \mathrm{KB}$, and $\mathrm{XL}$ designed the structure and fabricated the sample. $\mathrm{HZ}$ and HL performed the experiments. HY, HL, and KB wrote the manuscript with contribution from all the other authors. All authors participated in the discussion of the results.

\section{FUNDING}

This work was supported by the National Natural Science Foundation of China (Grant Nos. 51972033, 61774020, 51788104, 61672108, 11574311, and 61976025), Science and Technology Program of Shenzhen Science and Technology Innovation Commission (Grant Nos. JCYJ20180306173235924 and JCYJ20180305164708625).

3. Montalvao ESR, Montalvao ACPS, Campos ALPS, Gomes Neto A. A new model of metasurface used for linear-to-circular polarization conversion in antenna array. Microw Opt Technol Lett. (2016) 58:861. doi: 10.1002/mop.29681

4. Yu Z, Yu JG, Ran XY, Zhu CH. A novel ancient coin-like fractal multiband antenna for wireless applications. Int J Antennas Propag. (2017) 2017:6459286. doi: 10.1155/2017/6459286

5. Xu J, Guo Y, Yang P, Zhang R, Zhai X, Huang S, et al. Recent progress on RF orbital angular momentum antennas. J Electromagnet Wave. (2020) 34:275. doi: 10.1080/09205071.2019.1708814 
6. Zhang ZJ, Zhang WY, Zeadally S, Wang YA, Liu Y. Cognitive radio spectrum sensing framework based on multi-agent architecture for $5 \mathrm{G}$ networks. IEEE Wirel Commun. (2015) 22:34-9. doi: 10.1109/MWC.2015.7368822

7. Ran XY, Yu Z, Xie TY, Li Y, Wang XX, Huang P. A novel dual-band binary branch fractal bionic antenna for mobile terminals. Int J Antennas Propag. (2020) 2020:6109093. doi: 10.1155/2020/6109093

8. Kumar A, Sankhla V, Deegwal JK, Kumar A. An offset CPWfed triple-band circularly polarized printed antenna for multiband wireless applications. AEU-Int J Electron Commun. (2018) 86:133-41. doi: 10.1016/j.aeue.2018.02.002

9. Akhtar F, Naqvi SI, Arshad F, Amin Y, Tenhunen H. A flexible and compact semicircular antenna for multiple wireless communication applications. Radioengineering. (2018) 27:671-8. doi: 10.13164/re.2018.0671

10. Chen Y, Ye LF, Zhuo JL, Liu YH, Zhang L, Zhang $M$, et al. Frequency reconfigurable circular patch antenna with an arc-shaped slot ground controlled by PIN diodes. Int J Antennas Propag. (2017) 2017:7081978. doi: 10.1155/2017/7081978

11. Ullah S, Ahmad S, Khan BA, Tahir FA, Flint JA. An hp-shape hexa-band antenna for multi-standard wireless communication systems. Wirel Netw. (2019) 25:1361-9. doi: 10.1007/s11276-018-1760-x

12. Zhao Y. Design of high-gain, wideband antenna using microwave hyperbolic metasurface. AIP Adv. (2016) 6:055022. doi: 10.1063/1.4952752

13. Xu J, Bi K, Zhang R, Hao Y, Lan C, Mcdonald-Maier K, et al. A smalldivergence-angle orbital angular momentum metasurface antenna. Research. (2019) 2019:9686213. doi: 10.34133/2019/9686213

14. Almutairia AF, Islam MS, Samsuzzaman M, Islam MT, Misran N, Islam MT. A complementary split ring resonator based metamaterial with effective medium ratio for C-band microwave applications. Results Phys. (2019) 15:102675. doi: 10.1016/j.rinp.2019.102675

15. Xu JC, Hao YN, Bi K, Zhang R, Huang SG, Zhou J. Microwave orbital angular momentum beam generation based on circularly polarized metasurface antenna array. Eng Sci. (2019) 6:30-35. doi: 10.30919/es8d748

16. Patel SK, Kosta YP. Meandered multiband metamaterial square microstrip patch antenna design. Wave Random Complex. (2012) 22:475-87. doi: 10.1080/17455030.2012.723837

17. Fu X, Cui T. Recent progress on metamaterials: From effective medium model to real-time information processing system. Prog Quant Electron. (2019) 67:100223. doi: 10.1016/j.pquantelec.2019.05.001

18. Xu JC, Tao L, Zhang R, Hao YN, Huang SG, Bi K. Broadband complementary ring-resonator based terahertz antenna. Opt Express. (2017) 25:17099104. doi: 10.1364/OE.25.017099
19. Patel SK, Argyropoulos C, Kosta YP. Broadband compact microstrip patch antenna design loaded by multiple split-ring resonator superstrate and substrate. Wave Random Complex. (2017) 27:92-102. doi: 10.1080/17455030.2016.1203081

20. Gupta A, Bansal B, Mishra VK, Agrawal A. Miniaturised tri-band rhombus-shaped metamaterial-inspired antenna with gain enhancement using complementary closed ring resonators. IET Microw Antennas Propag. (2020) 14:185-93. doi: 10.1049/iet-map.2019.0567

21. Patchala K, Raja-Rao Y, Prasad AM. Triple band notch compact MIMO antenna with defected ground structure and split ring resonator for wideband applications. Heliyon. (2020) 6:e03078. doi: 10.1016/j.heliyon.2019.e03078

22. Ali W, Hamad E, Bassiuny M, Hamdallah M. Complementary split ring resonator based triple band microstrip antenna for WLAN/WiMAX applications. Radioengineering. (2017) 26:78-84. doi: 10.13164/re. 2017.0078

23. Zhou C, Wang GM, Wang YW, Zong BF, Ma J. CPW-Fed dual-band linearly and circularly polarized antenna employing novel composite right/lefthanded transmission-line. IEEE Antennas Wirel Propag Lett. (2013) 12:10736. doi: 10.1109/LAWP.2013.2279689

24. Xu J, Li RQ, Jiang XP, Wang SY, Han TC. Ultra-wideband linear polarization converter based on square split ring. Acta Phys Sin. (2019) 68:117801. doi: 10.7498/aps.68.20190267

25. Tao L, Xu JC, Li HH, Hao YN, Huang SG, Lei $M$, et al Bandwidth enhancement of microstrip patch antenna using complementary rhombus resonator. Wirel Commun Mob Com. (2018) 2018:6352181. doi: 10.1155/2018/6352181

26. Lan JX, Cao XY, Gao J, Han JF, Liu T, Cong LL, et al. Novel design of microstrip antenna array with low scattering performance. Acta Phys Sin. (2019) 68:034101. doi: 10.7498/aps.68.20181708

Conflict of Interest: The authors declare that the research was conducted in the absence of any commercial or financial relationships that could be construed as a potential conflict of interest.

Copyright (c) 2020 Yao, Liu, Zhu, Li, Dong and Bi. This is an open-access article distributed under the terms of the Creative Commons Attribution License (CC BY). The use, distribution or reproduction in other forums is permitted, provided the original author(s) and the copyright owner(s) are credited and that the original publication in this journal is cited, in accordance with accepted academic practice. No use, distribution or reproduction is permitted which does not comply with these terms. 